\title{
Job Satisfaction Among Nurses in the University of Port-Harcourt Teaching Hospital, Port-Harcourt, Nigeria
}

\author{
Eme Olukemi Asuquo ${ }^{1}$, John Abdulrahman Imaledo ${ }^{2,}$, , Chuma Thomp-Onyekwelu ${ }^{1}$, \\ Naomi Loretter Abara ${ }^{1}$, Chukwuemeka Chimezie Agugua ${ }^{1}$ \\ ${ }^{1}$ Department of Preventive and Social Medicine, Faculty of Clinical Sciences, College of Health Sciences, University of Port-Harcourt, \\ Port-Harcourt, Nigeria \\ ${ }^{2}$ Department of Health Promotion and Education, Faculty of Public Health, College of Medicine, University of Ibadan, Ibadan, Nigeria
}

\section{Email address:}

hisgracejohn@gmail.com (J. A. Imaledo)

${ }^{*}$ Corresponding Author

\section{To cite this article:}

Eme Olukemi Asuquo, John Abdulrahman Imaledo, Chuma Thomp-Onyekwelu, Naomi Loretter Abara, Chukwuemeka Chimezie Agugua. Job Satisfaction Among Nurses in the University of Port-Harcourt Teaching Hospital, Port-Harcourt, Nigeria. Central African Journal of Public Health. Vol. 3, No. 1, 2017, pp. 1-7. doi: 10.11648/j.cajph.20170301.11

Received: September 23, 2016; Accepted: November 5, 2016; Published: December 21, 2016

\begin{abstract}
Job satisfaction among Nurses was identified as an important factor and a key to achieving the Sustainable Goals in sub-Saharan Africa. It is therefore paramount to understand what motivates Nurses and to what extent they are satisfied with the organizations they work for and other contextual variables, this study therefore sought to provide information to fill in the gaps about job satisfaction among health professionals specifically Nurses in the Niger Delta region of Nigeria. A descriptive cross sectional design was adopted to explore the level of job satisfaction and organizational commitment among Nurses who were randomly selected from the twelve departments in the University of Port-Harcourt Teaching Hospital. The study revealed that more than half $(51 \%)$ of the respondents were satisfied with their jobs however, low pay, poor working conditions and low motivation were the principal causes of dissatisfaction. The management of the hospital should gear efforts towards correcting these lapses in order to achieve its organizational goal.
\end{abstract}

Keywords: Nurses, Job-satisfaction, Port-Harcourt, Dissatisfaction

\section{Introduction}

The technological trend has made it possible for health professionals to make comparisons on the international platform which to a large extent has been the bane of the dissatisfaction that health professionals in the third world countries face and as such made the movement of health personnel in search of better standard of living, quality of life, higher salaries, access to advanced technology and more stable political conditions in different places worldwide inevitable [1]. In recent past, more attention has been on the noticeable shortage of health workers in countries with the poorest health indicators including Nigeria, and the likely impact of this on the countries' ability to fight diseases and improve the health of her citizens [2] [3]. The World Health Organisation (WHO) affirmed that achieving the Millennium Development Goals (MDGs) in sub-Saharan Africa would be a mirage except the current workforce in some of its countries was scaled up by as much as $140 \%$ [4]. This shortage of workforce in Africa has been linked to mostly the rush from the third world countries to the developed countries of the world where the work environment is much better.

All over the world, health services are affected by many factors such as human resources, delivery systems and health infrastructures. Among these, human resources are a vital component in delivering health services. The relevance of job satisfaction in public health cannot be over-emphasised, this is because organizational and employees' health and wellbeing rest a great deal on job satisfaction [5] and because employees in a healthcare delivery system are expected to provide quality patient care while working in a highly stressful environment [6]. In fact, a country's human capital constitutes its most formidable asset and resource as they strive towards sustainable development in all its facets. Job 
satisfaction among professionals including those in the health sector is an important predictor of individual well-being, general life satisfaction and job performance. It is an important factor in patient care, and where there is job satisfaction it will have a positive impact on patient and health systems outcomes [7]. In his own summation, Spector states that job satisfaction influences people's attitude towards their jobs and various aspects of their jobs [8]. The result of this includes better performance and a reduction in withdrawal and counter-productive behaviours [9]. Job satisfaction among Nurses has been identified as a key factor in nurses' turnover with empirical literature suggesting that it is related to a number of organizational, professional and personal variables [10].

Many studies that have been conducted to assess job satisfaction among different health care professionals but given the critical role that Nurses play in determining the efficiency, effectiveness and sustainability of health care systems, it is paramount to understand what motivates them and to what extent they are satisfied with the organizations they work for and other contextual variables. This study sought to provide more information about job satisfaction among Nurses in Nigeria and the Niger Delta region of the country in particular. The study therefore, assessed the level of job satisfaction and organizational commitment among Nurses in the University of Port- Harcourt Teaching Hospital (UPTH).

\section{Methodology}

\subsection{Study Design}

A descriptive cross sectional design was adopted for this study and it explored the level of job satisfaction and organizational commitment among nurses in UPTH.

\subsection{Study Setting}

The study was carried out in UPTH located in Obio-Akpor Local Government Area of Port-Harcourt, Rivers State. The hospital, which is situated along the East-West Road of the city, is one of the major tertiary health institutions in the Niger Delta Region of Nigeria. It delivers services at primary, secondary and tertiary levels and has over 300 nursing staff and treats over 150,000 outpatients, over 10,000 inpatients and performs over 3,000 surgical operations per year.

\subsection{Study Population}

The study population consisted of Nurses who were recruited from the twelve departments in UPTH.

\subsection{Sampling Technique and Sample Size}

Simple random sampling was employed to select a total of 317 Nurses who had worked for at least a year from all the twelve departments in the hospital in December 2012. The number of Nurses selected from each department was done in proportion to the number of Nurses in each department. A total of 271 questionnaires were returned.

\subsection{Study Instrument}

A structured self-administered questionnaire was used to collect data from selected participants. The questionnaire consisted of two (2) sections. Section A consisted of the socio-demographic characteristics of the participants while Section B measured job satisfaction and consisted of an adaptation of the Organization Commitment Scale (OCS), consisting of 30 job satisfaction statements measured on a two-point scale ('True' or 'False'), developed by Meyer et al in 1993.

\subsection{Data Analysis}

The questionnaires were scrutinized for completeness, coded and entered into the computer and analyzed using the Statistical Package for Social Sciences (SPSS) software version 20.0. Descriptive and inferential statistical analysis was employed. Data was also summarized using graphic presentations for the interpretation of findings. The Chisquare test was used to assess the relationship between job satisfaction and organisational commitment among the nurses in UPTH. P-values less than 0.05 were considered significant.

\subsection{Ethical Considerations}

Respondents were intimated of the goals and objectives of the study before they were recruited. They were assured of confidentiality and no names were filled on the questionnaires. The questionnaires were given numbers to facilitate their entry and analysis and also to ensure anonymity of the respondents. Respondents were also told that they were free to withdraw from the study at any point.

\section{Results}

\subsection{Socio-demographic Characteristics of Respondents}

Table 1. Socio-demographic characteristics of respondents $(n=271)$.

\begin{tabular}{lll}
\hline s/n & Item & Frequency (\%) \\
\hline \multirow{3}{*}{1} & Gender & $260(95.9)$ \\
& Female & $11(4.1)$ \\
& Male & \\
& Tribe & $87(32.1)$ \\
& Igbo & $28(10.3)$ \\
& Yoruba & $156(57.6)$ \\
& others & \\
& Marital status & $169(62.4)$ \\
& Single & $90(33.2)$ \\
& Married & $6(2.2)$ \\
& Divorce/Separated & $6(2.2)$ \\
& Widowed & \\
& Years worked & $133(49.1)$ \\
& $1-5$ Years & $66(24.4)$ \\
& 6-10 Years & $39(14.4)$ \\
4 & 11-15 Years & $18(6.6)$ \\
& $16-20$ Years & $6(2.2)$ \\
& 21-25 Years & $9(3.3)$ \\
& $>25$ Years &
\end{tabular}


More of the respondents $(63.1 \%)$ were less than 40years, $95.9 \%$ were females and $32.1 \%$ of them claimed to be of Igbo extraction; majority $(62.4 \%)$ were single, $21 \%$ of them worked in the Internal Medicine Department (figure. 1) with a little less than half $(49.1 \%)$ who had a worked in the hospital for 1 to 5 years (table 1)

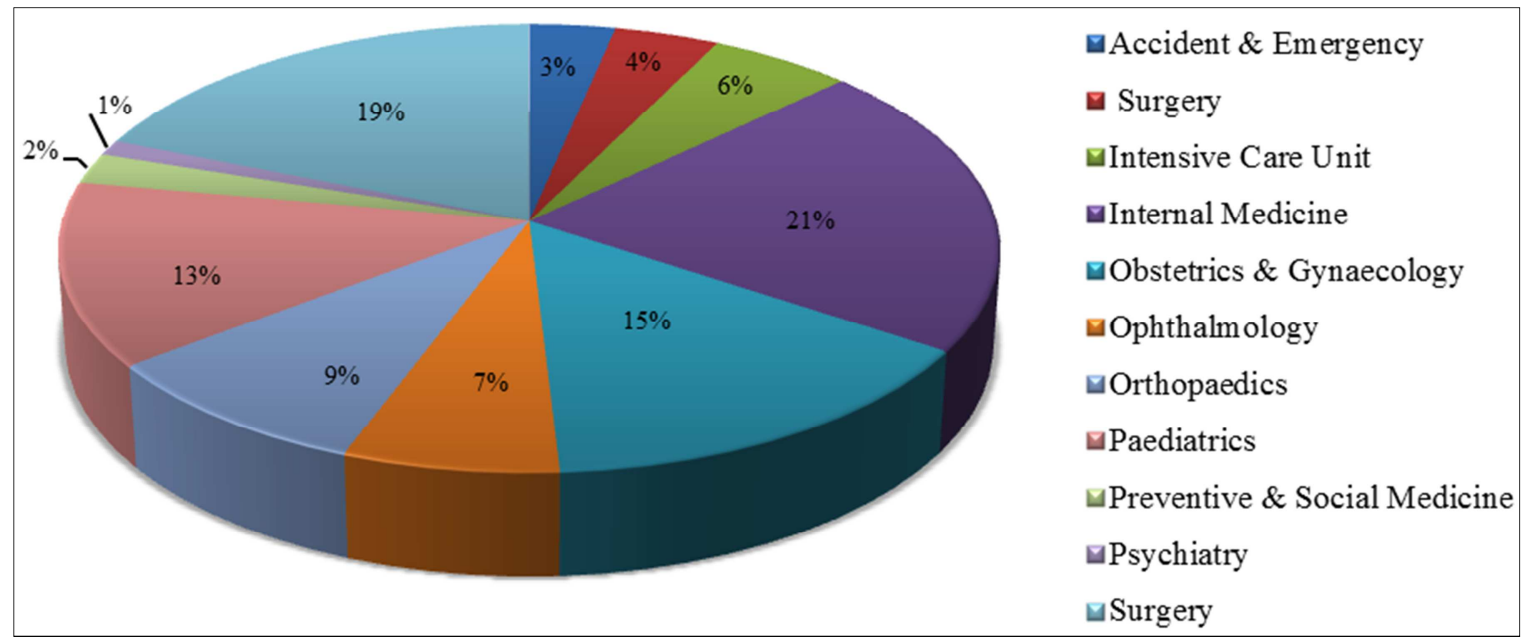

Figure 1. Respondents Department.

\subsection{Respondents Level of Job Satisfaction and Dissatisfaction}

Respondents were asked questions about their level of job satisfaction: $35 \%$ of them said they were satisfied with their job while $16 \%$ were very satisfied with their job (figure. 2 ). Twenty five percent of the respondents were dissatisfied with their jobs and some of the reasons given for this were: low pay $(25.5 \%)$, poor working conditions and work load $(23.6 \%)$, and poor promotion rates $(22.5 \%)$ (figure 3 ). Respondents were also asked how often they felt reluctant to go to work: $27.6 \%$ of them said 'not so often', $23.5 \%$ felt reluctant quite often and $23.1 \%$ rarely felt reluctant to go to work (table 2). However, $22.5 \%$ of the respondents felt reluctant to go to work for the same reasons as those given for job dissatisfaction, for $16.6 \%$ of them it was underachievement, $12.5 \%$ of them could not really tell why they felt reluctant to go to work, while $16.6 \%$ said personal reasons, $23.6 \%$ felt reluctant for unspecified reasons and $8 \%$ of them did not give an answer.

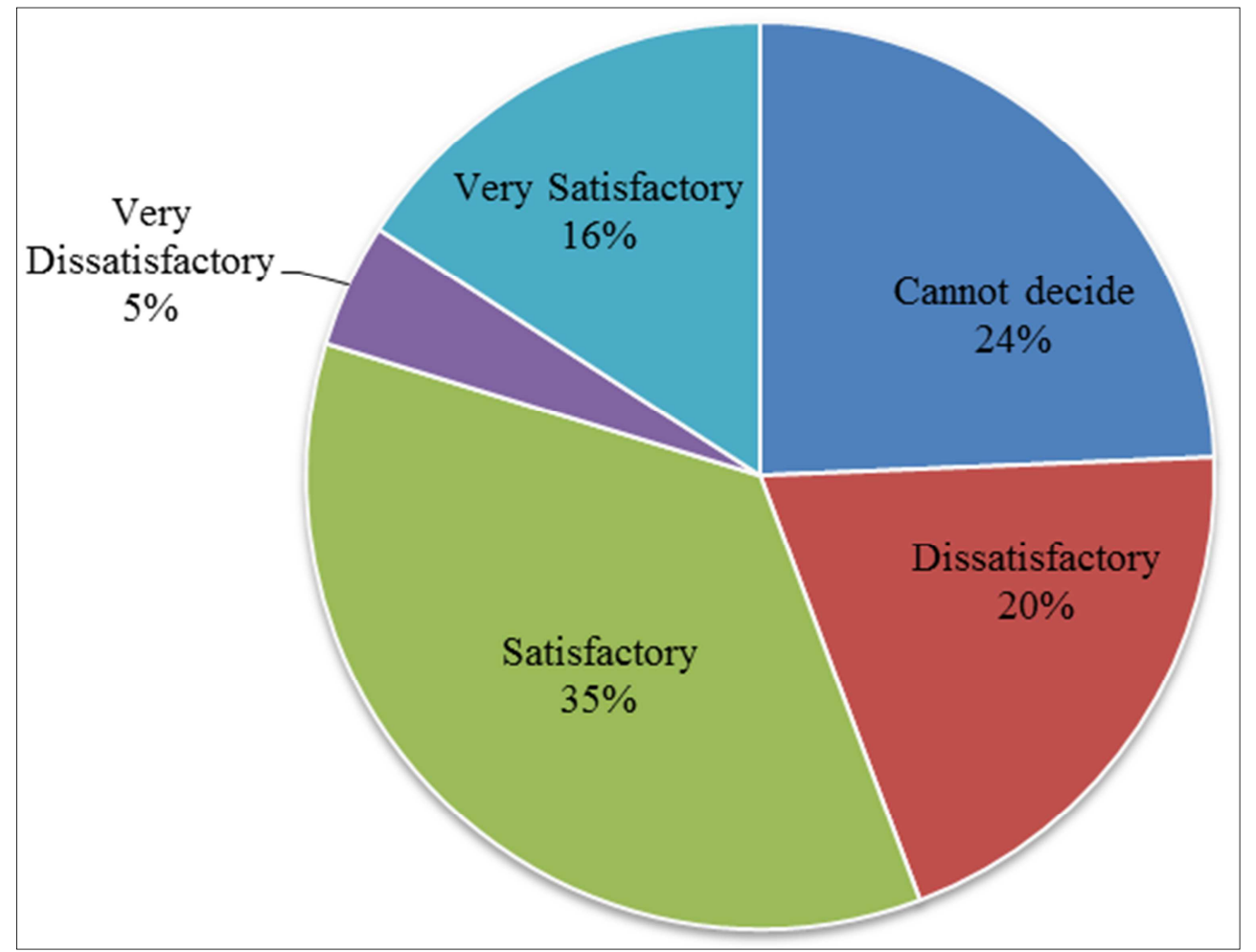

Figure 2. Respondents level of job satisfaction. 


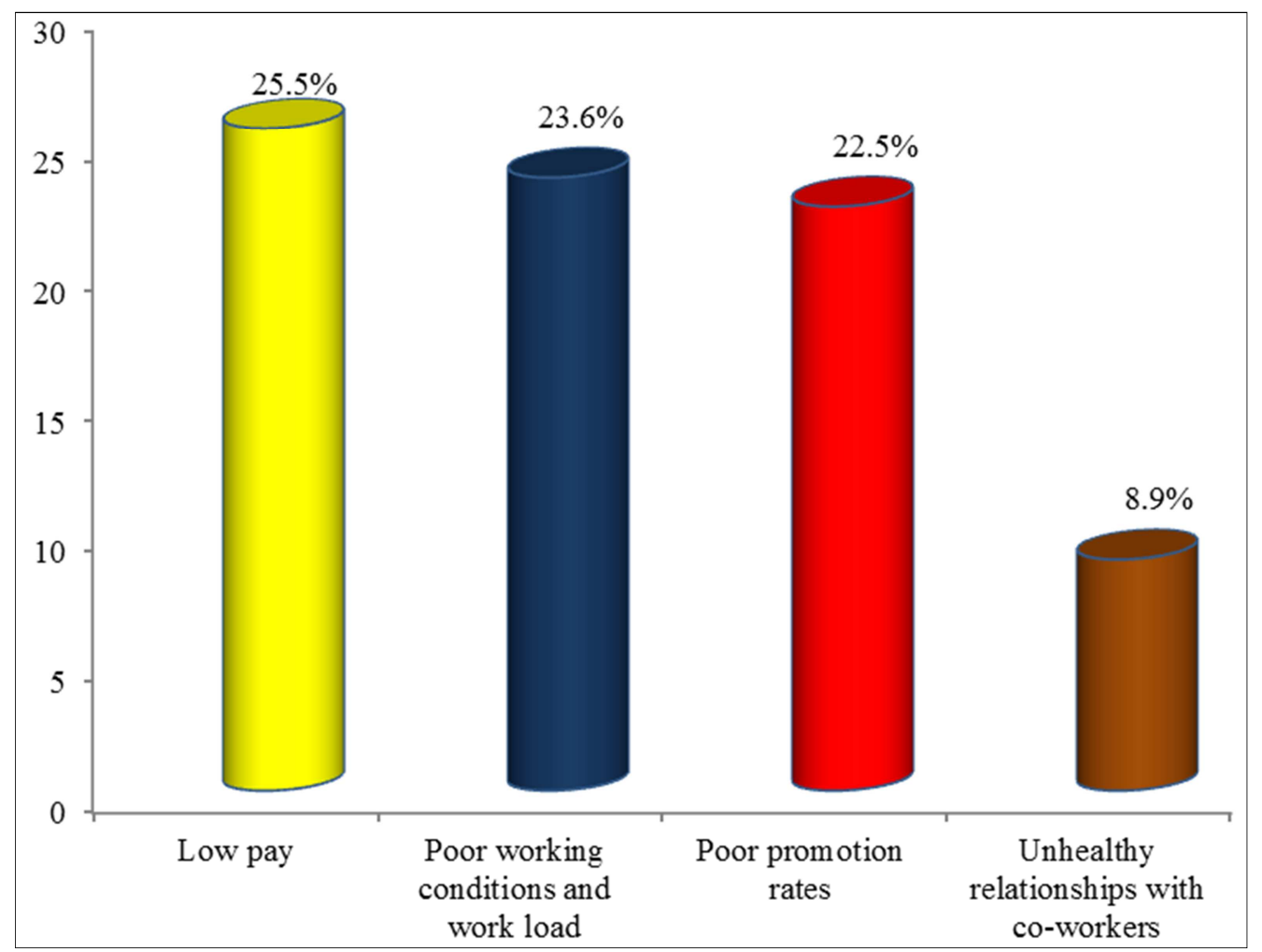

Figure 3. Reasons for job dissatisfaction among respondents.

Table 2. Times respondents felt reluctant to go to work ( $n=268)$.

\begin{tabular}{lll}
\hline $\mathbf{s} / \mathbf{n}$ & Statement & Freq (\%) \\
\hline 1 & Almost everyday & $16(5.9)$ \\
2 & Quite often & $63(23.5)$ \\
3 & Not so often & $74(27.6)$ \\
4 & Rarely & $62(23.1)$ \\
5 & Never & $53(19.8)$ \\
\hline
\end{tabular}

Respondents were also asked how often they were reluctant to go to work: for $27.3 \%$ not so often, $23.2 \%$ felt reluctant quite often and $22.9 \%$ rarely felt reluctant to go to work (table 2).

\subsection{Factors Affecting Respondents' Organizational Commitment}

Sixty-three $(23.4 \%)$ of the respondents were satisfied with their remunerations while $74.8 \%$ were not, $37.0 \%$ of them felt motivated to work for the hospital while $61.6 \%$ did not. Good co-workers relationship was reported by $52.6 \%$ while $47.0 \%$ felt otherwise; $59.2 \%$ were comfortable with the type and amount of work they were given to do, however, 106 (39.1\%) didn't feel the same way. Working conditions were good enough for $49.7 \%$ of the respondents but was not for $49.4 \%$. Also, while $64.1 \%$ respondents were satisfied with the supervision they received, $35.6 \%$ were dissatisfied.

\subsection{Requirements to Enhance Performance and Productivity in the Hospital}

Respondents claimed that to enhance productivity in the hospital the following would be required: adequate working equipment (41\%); better working conditions (14.4\%) and prompt and higher remuneration (14.1\%) (Table 3 )

Table 3. Requirements that can improve respondent's productivity.

\begin{tabular}{lll}
\hline s/n & Statement & Frequency (\%) \\
\hline 1 & Adequate and better working equipment & $164(41.4)$ \\
2 & Better working conditions and environment & $57(14.4)$ \\
3 & Prompt and better remuneration (pay) & $56(14.1)$ \\
4 & In-service training of manpower & $30(7.6)$ \\
5 & More manpower & $24(6.1)$ \\
6 & Mosquito control/ Mosquito free environment & $18(4.6)$ \\
7 & Good relationship among co-workers & $9(2.3)$ \\
8 & Incentives & $9(2.3)$ \\
9 & Better rate of promotion & $8(2.0)$ \\
10 & Better supervision & $6(1.5)$ \\
& Communication facilities and services in the & \\
11 & hospital for better means of communication & $4(1.0)$ \\
& with co-workers and supervisors. & $3(0.8)$ \\
12 & More facilities & $3(0.8)$ \\
13 & Motivation from supervisors & $3(0.8)$ \\
15 & Reward hard work & $(0.5)$ \\
\hline
\end{tabular}

*Multiple responses

\subsection{Respondents Views on the Best Thing About Nursing}

More of the respondents $(70.2 \%)$ are of the opinion that assisting humanity by offering care to the sick is the best thing about the nursing job, 5.5\% claimed that it was the opportunity to help others and make people happy that makes the nursing job worth-while and few $(3.6 \%)$ were of the view that nursing as a job gives them satisfaction (table 4) 
Table 4. Respondents' views on the best thing about the nursing profession.

\begin{tabular}{lll}
\hline s/n & Statement & Percentage \\
\hline 1 & Assisting humanity by offering care to the sick & 70.2 \\
2 & Opportunity to help others and make people happy & 5.5 \\
3 & Gives satisfaction & 3.6 \\
4 & Without nurses, there is no hospital & 3.3 \\
5 & Putting smiles on the faces of people & 2.6 \\
6 & Smart and neat dressing & 2.2 \\
7 & Deals with one's conscience & 1.8 \\
8 & Brings fulfilment & 1.8 \\
9 & Enjoy working with other members of the health team & 1.5 \\
10 & Meeting new people & 1.0 \\
11 & The pay is good & 1.0 \\
12 & It improves health of the population & 0.7 \\
13 & It saves lives & 0.7 \\
14 & Nothing excites me about the job & 2.9 \\
\hline
\end{tabular}

*Multiple responses

\subsection{Things Respondents'Do Not Like About the Nursing Profession}

Respondents also gave reasons for the things they do not like about the nursing profession. The following top the list of reasons given by respondents: night shift $(16.3 \%)$; exposure to infections (13.4\%) and lack of appreciation (12.7\%) (table 5)

Table 5. Things respondents' do not like about the nursing profession.

\begin{tabular}{lll}
\hline $\mathbf{s} / \mathbf{n}$ & Statement & Percentage \\
\hline 1 & Night shift & 16.3 \\
2 & Exposure to infections & 13.4 \\
3 & Lack of appreciation & 12.7 \\
4 & Too demanding and stressful & 11.2 \\
5 & Poor working conditions and equipment & 9.8 \\
6 & Poor salary & 9.4 \\
7 & Being looked down on by other medical personnel & 8.0 \\
8 & Death of a patient & 5.8 \\
9 & Poor promotion rates & 4.3 \\
10 & Poor supervision & 2.2 \\
11 & Lack of facilities & 1.1 \\
12 & Leaving everything for another & 1.1 \\
\hline
\end{tabular}

*Multiple responses

\section{Discussion}

The results of this study showed that most of the respondents were females; this may be due to the fact that the nursing profession is generally viewed as women's profession especially in Nigeria. This is similar to the findings of Lengu, Gundo, Maluwa \& Mbirimtengerenji which showed that all the Nurses that participated in their study were females [11]. A majority were of Igbo extraction; this is not unexpected since the study site is in the southsouth region of the country and it shares boundaries with the south-eastern states of the country, a region predominately occupied by the Igbos. Majority of the respondents also were single, this is different from the study of Lengu, et al which showed that virtually all Nurses that participated in their study were married [11]. The number of years the majority of respondents in this study had worked in the hospital is similar to that of the Nursing respondents in the study conducted by Lengu and his team [11].

\subsection{Respondents Level of Job Satisfaction and Dissatisfaction}

A little above half of the respondents were either satisfied or very satisfied with their job, this is similar with the results of other studies which showed that majority of the respondents were satisfied with their job [7] [12-13]. Reasons given in this study for job dissatisfaction included: low pay, poor working conditions and workload and poor promotion rates. This is found to be true in most studies conducted among health workers in the past in both the developed and developing countries of the world [14-20]

The study also revealed that more than a quarter of the respondents often felt reluctant to go work. This disposition may further confirm the assertion that job satisfaction is dependent on various variables which includes structure, size, pay, working conditions and leadership [21-23] some of which are already established in this study. The respondents gave various reasons why they felt reluctant to come to work, the major reason given was personal reasons, this also confirmed previous assertion that job dissatisfaction is often linked to personal reasons [23].

\subsection{Factors Affecting Respondents' Organizational Commitment}

Respondents in this study were asked questions on factors affecting their commitment to the organization that employed them. The results revealed that only (23.4\%) of the respondents were satisfied with their remuneration. This finding is not unexpected since studies in the past have also revealed that there is a relationship between job dissatisfaction and remuneration [21-24]. More than half of the respondents in this study felt motivated to work for UPTH. This result is supported by the findings of Angerami et al. which revealed that nurses' motives to remain in their jobs is related to their attachment to the nursing profession [25], even though their work was not recognized and they were poorly paid but differs from the assertion of Moore which found that a sense of professionalism is directly related to their intention to quit despite the impact of restructuring changes on hospital and nurse conditions, poor management communication style, and burnout [26].

Also, more than half of the respondents were comfortable with the type and amount of work they were given to do in UPTH, this is good since it has been found that there is a strong relationship between professional satisfaction and patient satisfaction and outcomes. Conversely other studies showed that Nurses who were not satisfied at work were also found to distance themselves from their patients and their nursing chores, resulting in poor quality of care [27-28]. These finding will help policy makers and management know areas they need to concentrate attention on for improvement if the goal of increased productivity and service improvement is to be achieved. Almost half of the respondents were satisfied with their working conditions and more than a quarter were satisfied with the supervision they received. This finding is contrary to what is obtainable in the health 
sector that has been riddled with series of strikes in the last few years as a result of poor working conditions which has been confirmed to be a perquisite for absolute commitment to their job [18]

\subsection{Respondents' Suggestions on Requirements to Enhance Performance and Productivity in the Hospital}

Respondents made suggestions about things needed to enhance performance and productivity, these included: adequate working equipment; better working conditions and prompt and higher remuneration. These are necessary for improvement in productivity which to a large extent is lacking in most developing countries including Nigeria and it has been asserted that improvement in remuneration and working conditions of health care staff and rationalization of work would lead to increased job satisfaction and contribute to the overall quality of health services [29]. This finding is similar to the findings of a study conducted in Ethiopia where respondents made suggestions which included motivation of staff through different incentives such us bonuses, house allowances, salary increment, establishing good administration management systems and improving hospital facilities and infrastructure in order to enhance performance and productivity in the hospital [30].

\subsection{Respondents' Views on What They Love or Hate About the Nursing Profession}

Respondents expressed various views about what they love or hate about nursing as a profession; topping the list is assisting humanity and night shift respectively. This study revealed that the fundamental principle of the nursing profession which include the nature of their job description (night- shift) is the major reason Nurses are in the profession, one would expect then that they should be able to give their best to their job and not complaining about shifting nature of the job. The managerial prowess needs to be strengthened and looked into if the best will ever be gotten from Nurses in health service delivery in Nigeria [31-33].

\section{Conclusion}

This study revealed that more than half of the respondents were satisfied with their jobs with low pay and negative attitudes towards working conditions as the principal causes of dissatisfaction and low motivation; the management of the hospital should gear efforts towards correcting this lapse in order to achieve its organizational goals.

\section{Recommendations}

The following are hereby recommended if these goals are to be achieved:

(1) Provision of adequate working equipment with better facilities

(2) Better working conditions with healthier working relationship amongst co-workers and in-service training of workers

(3) Prompt and higher remuneration with motivational incentives

(4) More hands and better manpower with better supervision to reduce the tedium of night shifts

(5) Better appreciation and recognition of nurses by other members of the health team

\section{References}

[1] Dodani S, LaPorte RE. Brain drain from developing countries: how can brain drain be converted into wisdom gain? Journal of the Royal Society of Medicine; 2005; 98: 487-91.

[2] Chen L, Evans T, Anand S, Boufford JI, Brown H, Chowdhury $\mathrm{M}$, et al., et al. Human resources for health: overcoming the crisis. Lancet; 2004; 364: 1984-90 doi: 10.1016/S01406736(04)17482-5 pmid: 15567015.

[3] Narasimhan V, Brown H, Pablos-Mendez A, Adams O, Dussault G, Elzinga G, et al., et al. 2004. Responding to the global human resources crisis. Lancet; 363: 1469-72 doi: 10.1016/S0140-6736(04)16108-4 pmid: 15121412.

[4] United Nations Millennium Development Goals [Home page] (2009). Available from: http://www.un.org/millenniumgoals/ [accessed on 23 January 2015].

[5] Faragher EB, Cass M, Cooper CL. The relationship between job satisfaction and health: a meta-analysis. Occup Environ Med; 2005; 62: $105 \_12$.

[6] Dolan N. The relationship between burnout and job satisfaction in nurses. J Adv Nurs; 1987; 12: 3 _ 12.

[7] Yami A, Hamza L, Hassen A, Jira C, Sudhakar M. Job satisfaction and its determinants among health workers in Jimma University Specialized Hospital, southwest Ethiopia. Ethiop J Health Sci; 2011; 21: 19_27.

[8] Spector, P. Job Satisfaction: Application, Assessment, Causes and Consequences. California: Sage. 1997.

[9] Morrison, R. Negative relationships in the workplace: Associations with organizational commitment, cohesion, job satisfaction and intention turnover, Journal of Management and Organization, 2008; 14: 330-344.

[10] Kekana HP, Du Rand EA, van Wyk NC. Job satisfaction of registered Nurses in a community hospital in the Limpopo Province in South Africa. Curationis; 2007; 30(2): 24-35.

[11] Lengu E S, Gundo R, Maluwa \& Mbirimtengerenji N. Compliance of state registered nurses to nursing standards during practice in tertiary facilities in Malawi Open Journal of Nursing, 2013; $3, \quad 395-399 \quad$ OJN http://dx.doi.org/10.4236/ojn.2013.35053

[12] Omolase CO., Seidu MA., Omolase BO. \& Agborubere D E. Job satisfaction amongst Nigerian ophthalmologists: an exploratory study. Libyan J Med, 2010; 5: 4629-DOI: 10.4176/091010

[13] Blaauw D, Ditlopo P, Maseko F, Chirwa M, Mwisongo A Bidwell P, Thomas S \& Normand C. Comparing the job satisfaction and intention to leave of different categories of health workers in Tanzania, Malawi, and South Africa. Glob Health Action, 2013; 6: 19287http://dx.doi.org/10.3402/gha.v6i0.19287 
[14] Trends and insights 2004. (available online at: http://www.mckesson.ca/documents/trends2004.pdf). Accessed on 10/12/2015.

[15] Government of Ethiopia and the World Bank. Health Sector Review, Ethiopian social sector studies. Addis Ababa: Mega, 1st Ed. 2004

[16] Agyepong IA, Anafi P, Asiamah E, Ansah EK, Ashon DA, Narh-Dometey C. Health worker (internal customer) satisfaction and motivation in the public sector in Ghana. Int $\mathrm{J}$ Health Plann Manage. 2004; 19: 319-336.

[17] Sveinsdottir H, Biering P, Rahel A. Occupational stress, job satisfaction and working environment among Icelanding nurses: A cross-sectional questionnaire survey. Int J Nurs Stud. 2006; 43: 875-89.

[18] Pillay R. Work satisfaction of professional nurses in South Africa: acomparative analysis of the public and private sectors. Hum Resour Health. 2009; 7: 15.

[19] Chirwa ML, Greeff M, Kohi TW, Naidoo JR, Makoae LN, Dlamini PS, Kaszubski C, Cuca YP, Uys LR, Holzemer WL. 2009. HIV stigma and nurse job satisfaction in five African countries. J Assoc Nurses AIDS Care 20: 14-21.

[20] Lorber and Skela-Savič:. Job satisfaction of nurses in Slovenian Hospitals, Croat Med J. 2012; 53: 263-70.

[21] Finn CP. Autonomy: an important component for nurse's job satisfaction. International Journal of Nursing Studies, 2001; 38 (3): 349-357.

[22] Sempane, M., Rieger, H. \& Roodt, G. Job satisfaction in relation to organizational culture, South African Journal of Industrial Psychology, 2002; 28 (2): 23-30.

[23] Lu H, While AE, Barriball KL: 2005. Job satisfaction among nurses: a literature review. Int J Nurs Stud, 42: 211-227.

[24] O'Rourke K, Allgood C, Vanderslice J, Hardy MA: 2000. Job satisfaction among nursing staff in a military health care facility. Military medicine, 165 (10): 757-761.

[25] Angerami, E. L., Gomes, D. L., Mendes, I. J. Permanence of nurses in their profession. Revista Latino-Americana de Enfermagem 2000; 8 (5), 52-57 [Article in Portuguese].

[26] Moore, K. A. Hospital restructuring: impact on nurses mediated by social support and a perception of challenge. Journal of Health and Human Services Administration. 2001; 23 (4), 490-517.

[27] Demerouti E, Bekker A, Nachreiner F, Schaufeli W. A model of burnout and life satisfaction amongst nurses. Journal of Advanced Nursing, 2000; 32 (2): 454-464.

[28] Tzeng HM. The influence of nurses' working motivation and job satisfaction on intention to quit an empirical investigation in Taiwan. International Journal of Nursing Studies, 2002; 39: 867-878.

[29] Bodur S. Job satisfaction of health care staff employed at health centres in Turkey. Occup. Med. 2002; Vol. 52 No. 6, pp. 353-355.

[30] Alemshet Y., Leja H., Alima H., Challi J. \& Morankar S. Job Satisfaction and its Determinants. Ethiop J Health Science; 2011; 21: 19-27.

[31] Judge T. A and Church A. H. Job satisfaction research and practice in industrial and organizational psychology: Linking theory with practice. Oxford, United Kingdom: Blackwell, Cooper C. L and Locke E. A (eds), (pp. 168-198). 2000.

[32] Bodur S. Job satisfaction of health care staff employed at health centres in Turkey. Occup. Med. 2002; Vol. 52 No. 6, pp. 353-355.

[33] Bravendam. Research Incorporated. Effective management through measurement: Special report. 2002. Retrieved from http://www.employeesatisfactions.com/ on September 20, 2015 